\title{
UV Characteristics and Performance as Positive-Working Deep, Mid, and Near UV Resists of Phenyl Isopropenyl Ketone Copolymers
}

\author{
Kazuyuki Sugita, Nobuo Ueno, Kieko Harada, \\ Masahito Kushida, Yasushi Suzuki, Yasunori TaKeUchi, ${ }^{*}$ \\ and James GuILLET* \\ Faculty of Engineering, Chiba University, Inage-ku, Chiba 263, Japan \\ * Department of Chemistry, University of Toronto, St. George St., \\ Toronto M5S 1A1, Canda
}

(Received February 18, 1993)

\begin{abstract}
Phenyl isopropenyl ketone (PIPK) was copolymerized with styrene and methyl methacrylate (MMA). UV characteristics, resist sensitivity, and durability against $\mathrm{O}_{2}$ reactive ion etching (RIE) were studied on copolymers containing various amounts of PIPK. The copolymers had stronger absorption in the deep, mid, and near UV region and fairly large quantum yield for main chain scission of $0.19-0.37$. Both sensitivity and $\mathrm{O}_{2}$ RIE durability increased at the same time as PIPK content in the MMA copolymer increased, though sensitivity and dry-etching durability of positive-working resists are generally in a trade-off relationship. The sensitivities obtained with the MMA copolymer containing $35 \mathrm{~mol} \%$ of PIPK were $250 \mathrm{~mJ} \mathrm{~cm}^{-2}$ at $313 \mathrm{~nm}$ and $390 \mathrm{~mJ} \mathrm{~cm}^{-2}$ at $365 \mathrm{~nm}$. The sensitivity at $254 \mathrm{~nm}$ was the highest at the PIPK content of $16 \mathrm{~mol} \%$ and 810 times as high as that of PMMA, but bleaching characteristics were insufficient at this wavelength.
\end{abstract}

KEY WORDS Absorptivity / Bleaching / Main Chain Scission / Quantum. Yield / Sensitivity / Dry Etching / $\mathrm{O}_{2}$ Reactive Ion Etching / Durability / Aromatic Ketone / Methyl Methacrylate Copolymer /

Increase of packaging density and shrinkage of pattern size of electronic devices require UV resists of excellent performance including high sensitivity, resolution, and dry-etching durability. Phenyl isopropenyl ketone (PIPK) chromophore is highly sensitive to UV radiation, and its copolymer with methyl methacrylate (MMA) has been reported to be 110-times as sensitive as PMMA when exposed to a Xe-Hg lamp. ${ }^{1}$ In addition, since PIPK contains an aromatic moiety, the copolymer is expected to have improved durability against reactive ion etching (RIE). UV characteristics of the resist film should be studied, because photochemistry of ketone polymers is well documented and it is reported that the copolymer degrades by $\alpha$-cleavage with split- ting benzoyl radical. ${ }^{2,3}$ Therefore, bleaching may occur if cleavage brings about hypo- or hypsochromic shift of absorption band, or if the chromophore escapes from the polymer matrix after splitting.

In this study, we prepared PIPK copolymers with styrene (St) and MMA. Quantum yield for main chain scission was measured on the St copolymer at the wavelength to be mentioned next in order to be compared with those in the previous papers. ${ }^{4,5}$ Resist sensitivities at 254,313 , and $365 \mathrm{~nm}$, and $\mathrm{O}_{2}$ RIE durability as well as UV characteristics were investigated on MMA copolymers containing various amounts of PIPK. The wavelength was selected by considering the emission lines of mercury lamps and gas lasers used for pattern transfer 
of electronic devices.

\section{EXPERIMENTAL}

\section{Materials}

PIPK was prepared from propiophenone by Mannich reaction followed by deamination, and copolymerized with styrene (PSt-PIPK) by emulsion polymerization with ammonium persulfate as an initiator as described in the previous paper. ${ }^{4}$ The copolymer of PIPK with MMA (PMMA-PIPK) was prepared in suspension or in bulk by using AIBN initiator. The ketone monomer content incorporated in PSt-PIPK was estimated from the characteristic absorption band due to $v(\mathrm{C}=\mathrm{O})$ at $1655-1685 \mathrm{~cm}^{-1}$ in the IR spectrum measured on the polymer layer on a $\mathrm{NaCl}$ disk. In the calculation, the molar absorptivity of the carbonyl band was assumed equal to that of the band in phenyl vinyl ketone homopolymer. The ketone monomer content in PMMA-PIPK was estimated from the absorbance at $280 \mathrm{~nm}$ in the UV spectrum in $\mathrm{CHCl}_{3}$, regarding the molar absorptivity was equal to that of propiophenone. Molecular weight of the copolymers was calculated from intrinsic viscosity number, $[\eta]$, using the constants for PSt and PMMA homopolymers. ${ }^{6}$ Polymer data are summarized in Table I. Besides the copolymers shown in Table I, PMMA $\left(M_{w}=604000\right)$, poly $(\alpha$-methyl styrene) (PMSt, $\left.M_{w}=192000\right)$, and poly(phenyl vinyl ketone) (PPVK) were used for measurements as controls.

\section{Quantum Yield Measurement}

A dilute polymer solution $\left(0.25-0.4 \mathrm{~g} \mathrm{dl}^{-1}\right)$ placed in a quartz cell was irradiated by UV light from a high pressure mercury lamp (OSRAM-HBO, 100W) at desired wavelength selected with an interference filter placed after a band pass filter UG-1 $(300 \mathrm{~nm}<\lambda<400 \mathrm{~nm})$ for $366 \mathrm{~nm}$ and $313 \mathrm{~nm}$, or after a flow cell filled with water for $254 \mathrm{~nm}$ irradiation to remove longer wavelength light especially in the infrared region. The polymer solution in the quartz cell was held in an aluminum block kept at a desired temperature. The solution was purged with nitrogen to remove oxygen prior to irradiation. The polymer solution was transferred to an automatic viscometer after desired irradiation time to measure the viscosity to follow molecular weight change, and then returned into the quartz cell for further irradiation. Ferrioxalate actinometry ${ }^{7,8}$ was performed just after each irradiation. Incident light intensity, $I_{0}$, was $4.05 \times 10^{-10}$ einstein $\mathrm{s}^{-1} \mathrm{~cm}^{-2}$. All procedures were done in a darkened room. Evaporation of solvent

Table I. Copolymerization of PIPK with St and MMA

\begin{tabular}{|c|c|c|c|c|c|c|}
\hline & \multirow{2}{*}{$\begin{array}{c}\text { PIPK in feed } \\
\text { mol } \%\end{array}$} & \multirow{2}{*}{$\begin{array}{c}\text { Method of } \\
\text { polymn. }\end{array}$} & \multirow{2}{*}{$\frac{\text { Conversion }}{w t \%}$} & \multirow{2}{*}{$\frac{\begin{array}{c}\text { PIPK in } \\
\text { copolymer }\end{array}}{\mathrm{mol} \%}$} & \multirow[t]{2}{*}[\eta]{} & \multirow[t]{2}{*}{$M_{w}{ }^{\mathrm{c}}$} \\
\hline & & & & & & \\
\hline PSt-PIPK & 7.6 & Emulsion & 94.4 & $8.5^{\mathrm{a}}$ & $0.34^{\mathrm{b}}$ & 88000 \\
\hline PMMA-PIPK 06 & 10 & Suspension & 71.1 & $5.8^{a^{\prime}}$ & $0.06^{\mathbf{b}^{\prime}}$ & 12000 \\
\hline PMMA-PIPK 16 & 35 & Suspension & 13.7 & $15.8^{a^{\prime}}$ & $0.06^{b^{\prime}}$ & 12000 \\
\hline PMMA-PIPK 17 & 45 & Bulk & 24.6 & $17.0^{\mathrm{a}^{\prime}}$ & $0.10^{b^{\prime}}$ & 25000 \\
\hline PMMA-PIPK 27 & 65 & Bulk & 4.3 & $27.0^{a^{\prime}}$ & $0.05^{b^{\prime}}$ & 10000 \\
\hline PMMA-PIPK 35 & 61 & Bulk & 24.4 & $35.0^{\mathrm{a}^{\prime}}$ & $0.05^{b^{\prime}}$ & 10000 \\
\hline
\end{tabular}

a Calculated from absorption at $1655-1685 \mathrm{~cm}^{-1}$ with a solid film.

a' Calculated from absorption at $280 \mathrm{~nm}$ in chloroform.

b Measured in toluene at $30^{\circ} \mathrm{C}$.

$b^{\prime}$ Measured in butanone at $25^{\circ} \mathrm{C}$.

c Calculated from $[\eta]$ by using $\mathrm{K}$ and $\alpha$ for PSt and PMMA homopolymers. 
during the measurement was compensated for by monitoring concentration of a polystyrene solution under the same conditions as actual run. The number of moles of main chain scission was calculated from the viscosity by the method described before, ${ }^{4}$ assuming random molecular weight distribution and random chain scission. ${ }^{9}$

\section{Specimen Preparation}

PMMA-PIPK copolymer layers were prepared by spincoating from toluene solutions onto quartz or copper-evaporated glass plates, and prebaked in an air-circulating oven at $180^{\circ} \mathrm{C}$ for $20 \mathrm{~min}$. They were used for spectral measurements and the study of resist performance, respectively.

\section{Sensitivity and Contrast}

A polymer specimen was irradiated at room temperature with $365 \mathrm{~nm}$ near UV and $313 \mathrm{~nm}$ mid UV monochromatic light from a superhigh-pressure mercury (SHP Hg) lamp (SHL100UV, 75W, or USH-250D, 250W) through a glass filter UV-D2 and through a glass filter UV-D25 + an interference filter + a slide-glass $(\lambda>300 \mathrm{~nm})$, respectively. Irradiation of 254 nm deep UV light was done, using a lowpressure mercury lamp (Toshiba lamp, 6W) without a filter. Radiation in mid and near UV region from a SHP $\mathrm{Hg}$ lamp with no filter was also exposed to get sensitivity to compare with values in the literature. ${ }^{1}$ The intensity of each radiation was measured with a thermopile, Eppley Thermopile of air-type.

The irradiated specimen was developed by dipping in a developer without agitation, rinsed and postbaked at $140^{\circ} \mathrm{C}$ for $20 \mathrm{~min}$. The developed depth, which was the difference of film thickness between the exposed and the unexposed areas, was measured with an interference microscope after evaporating aluminum onto the surface of the specimen. The remaining resist thickness was obtained by reducing the depth from the thickness in the unexposed area, and plotted against the logarithm of varying radiation energy to give the characteristic curve. The sensitivity, $D_{400}$, was defined in this study as the minimum incident radiation energy (in $\mathrm{J} \mathrm{cm}^{-2}$ ) required for a removal depth of $400 \mathrm{~nm}$ after development. The contrast, $\gamma$, was obtained as the slope of the linear part of the characteristic curve for the resist film of $400 \mathrm{~nm}$ thick.

\section{Dry Etching Durability}

$\mathrm{O}_{2}$ RIE was performed with a parallel-plate etching reactor (plate disk $100 \mathrm{~nm}^{\phi}$, plate distance $25 \mathrm{~mm}$ ) constructed in our laboratory. Working $\mathrm{O}_{2}$ pressure was fixed to 0.2 Torr and net power of $13.56 \mathrm{MHz}$ discharge was to $50 \mathrm{~W}$. Since the sample holder was equipped with a water-cooling system, temperature rise was suppressed to such a small extent that after 100 s etching was $13-17$ degree. Therefore, this etching experiment was carried out at low enough temperature below the glass transition temperature. In order to make experimental error as small as possible, 8-12 specimens including the control were etched at the same time. The etched depth, measured by the method similar to the developed depth above-mentioned, was plotted against etching time, and the slope of the linear plot was regarded as the etching rate. Durability was estimated by a reciprocal ratio of the RIE rate to that of the PMMA standard.

\section{RESULTS AND DISCUSSION}

\section{Quantum Yield for Main Chain Scission}

Prior to quantum yield measurement, UV spectra of PSt-PIPK in 1,2-dichloroethane (DCE) were measured with a Hewlett Packard 8451A Spectrophotometer against the solvent as a reference. The absorption maximum was observed at $242 \mathrm{~nm}\left(\varepsilon=7.37 \times 10^{3} 1 \mathrm{~mol}^{-1} \mathrm{~cm}^{-1}\right)$ and two shoulders were around $270 \mathrm{~nm}$ and $290 \mathrm{~nm}$. The molar absorptivity, $\varepsilon$, was $5.72 \times 10^{3}$ at $254 \mathrm{~nm}$. Figure 1 shows a plot of moles of main chain scission (or break), $S$, vs. absorbed $254 \mathrm{~nm}$ light, $I \cdot t$, where $I$ is the 


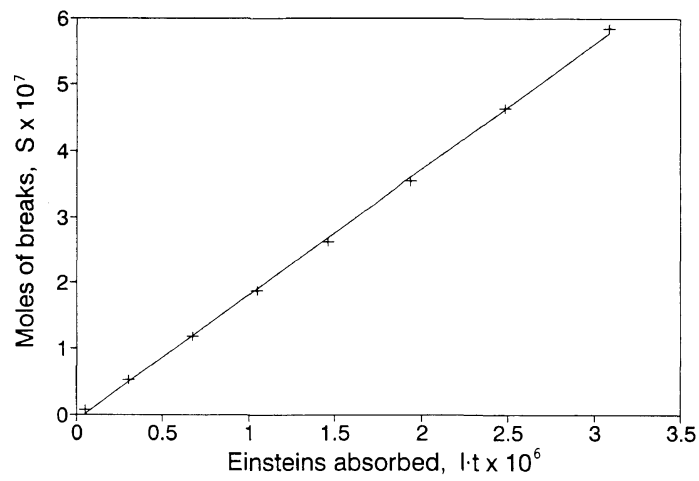

Figure 1. Plot of moles of breaks, $S$, vs. absorbed light, $I \cdot t$, for PSt-PIPK (in 1,2-dichloroethane at $254 \mathrm{~nm}$ exposure).

Table II. Quantum yield of main chain scission for PSt-PIPK

\begin{tabular}{|c|c|c|c|}
\hline \multicolumn{2}{|c|}{$254 \mathrm{~nm}$} & \multirow{2}{*}{$\begin{array}{c}313 \mathrm{~nm} \\
\text { benzene } \\
\left(25^{\circ} \mathrm{C}\right)\end{array}$} & \multirow{2}{*}{$\begin{array}{c}364-366 \mathrm{~nm} \\
\mathrm{DCE}^{\mathrm{a}} \\
\left(30^{\circ} \mathrm{C}\right)\end{array}$} \\
\hline $\begin{array}{l}\mathrm{DCE}^{\mathrm{a}} \\
\left(30^{\circ} \mathrm{C}\right)\end{array}$ & $\begin{array}{c}\text { dioxane } \\
\left(30^{\circ} \mathrm{C}\right)\end{array}$ & & \\
\hline 0.19 & $0.12^{\mathrm{d}}$ & $\begin{array}{l}0.36-0.37^{\mathrm{b}} \\
0.06-0.15^{\mathrm{e}}\end{array}$ & $0.26^{\mathrm{c}}$ \\
\hline
\end{tabular}

a 1,2-Dichloroethane.

b From 5.

c From 4.

d From 3.

e From 2, quantum yield decreases as PIPK content becomes larger.

number of photons (in einstein) absorbed by the chromophore in the polymer per unit time, and $t$ is the period of irradiation. From the slope of this plot, the quantum yield of main chain scission, $\Phi_{\mathrm{cs}}$, was determined as 0.19 at $254 \mathrm{~nm}$.

This value is compared in Table II with those at $313 \mathrm{~nm}$ and $365 \mathrm{~nm}$ previously measured with the same automatic viscometer by our group $^{4,5}$ or reported by Naito et al. ${ }^{2,3}$ Ketone polymers undergo various photochemical reactions including $\alpha$-cleavage (Norrish type I reaction), hydrogen atom abstraction (Norrish type II reaction, or photocyclization to form cyclobutanols), charge-transfer complexation (photocycloaddition or photoreduction), and elimination of $\alpha$-substituents (in the case of carbonyl compounds containing hetero-atom substituents in the $\alpha$-position), in addition to photophysical processes. ${ }^{10}$ Among photochemical processes, both type II reaction and type I reaction followed by $\beta$-scission cause main chain scission which can be detected as the viscosity decrease. The lower quantum yield at $254 \mathrm{~nm}$ suggests lower efficiency of the two reactions in the deep UV region than in the mid and near UV region. It is likely that the larger the energy of photon becomes, the smaller the selectivity of a definite chemical reaction becomes in all energy-dissipation processes.

We speculate the reason for the smaller selectivity as follows: two kinds of Norrish type I reactions are possible in the case of the ketone polymer investigated here,

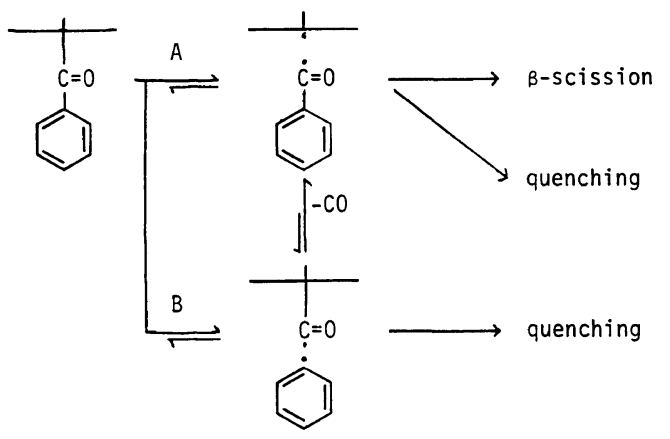

The intermediate of Scheme A can degrade directly by $\beta$-scission, while that of Scheme B degrade by $\beta$-scission only after splitting of $\mathrm{CO}$, and, therefore, quantum yield for main chain scission, $\Phi_{\mathrm{cs}}$, of the former is higher than that of the latter. The $\mathrm{C}-\mathrm{C}$ bond between $\mathrm{C}=\mathrm{O}$ and aromatic ring is stabilized by resonance compared with the $\mathrm{C}-\mathrm{C}$ bond adjacent to the main chain, so Reaction $A$ is expected to occur more easily than Reaction B. Excitation with photons of smaller energy will initiate Reaction A with larger probability. However, if the polymer is excited with photons of larger energy, Reaction B may take place with the probability similar to Reaction $\mathrm{A}$, i.e., with 
relatively larger probability. Consequently the total quantum yield may become lower.

\section{UV Absorption Characteristics}

UV spectra of thin films of MMA copolymers containing various amounts of PIPK are shown in Figure 2. Absorption maxima were observed at $242 \mathrm{~nm}(\varepsilon=1.27 \times$ $\left.10^{4}\right)$ and $320 \mathrm{~nm}(\varepsilon=87)$. The molar absorptivities, $\varepsilon$ at $254 \mathrm{~nm}, 313 \mathrm{~nm}$, and $365 \mathrm{~nm}$ were 7600 , 86 , and 7.7, respectively, which were obtained as average values of the four copolymers. Since the absorption at $254 \mathrm{~nm}$ was strong, bleaching characteristics were studied by measuring the
UV spectra before and after irradiation. When $3.25 \mathrm{~J} \mathrm{~cm}^{-2}$ of $254 \mathrm{~nm} \mathrm{UV} \mathrm{light} \mathrm{was} \mathrm{irradiated}$ as shown in Figure 3, the absorbance of PMMA-PIPK's 06, 17, and 35 decreased to $37 \%, 70 \%$, and $74 \%$ of the initial values, respectively. Partial bleaching was observed on PMMA-PIPK 06, but the bleaching characteristics of PMMA-PIPK's 17 and 35 were insufficient. It was considered that the photoproducts of low molecular weight could not escape from the solid film during irradiation at room temperature, since the glass transition temperature of the copolymer was high enough above room temperature.
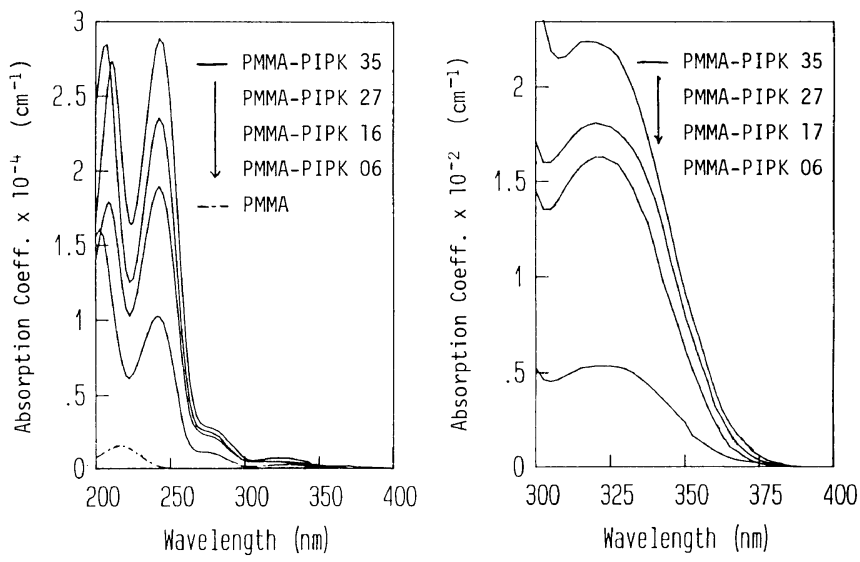

Figure 2. UV spectra of PMMA-PIPK and PMMA (solid film on a quartz plate).
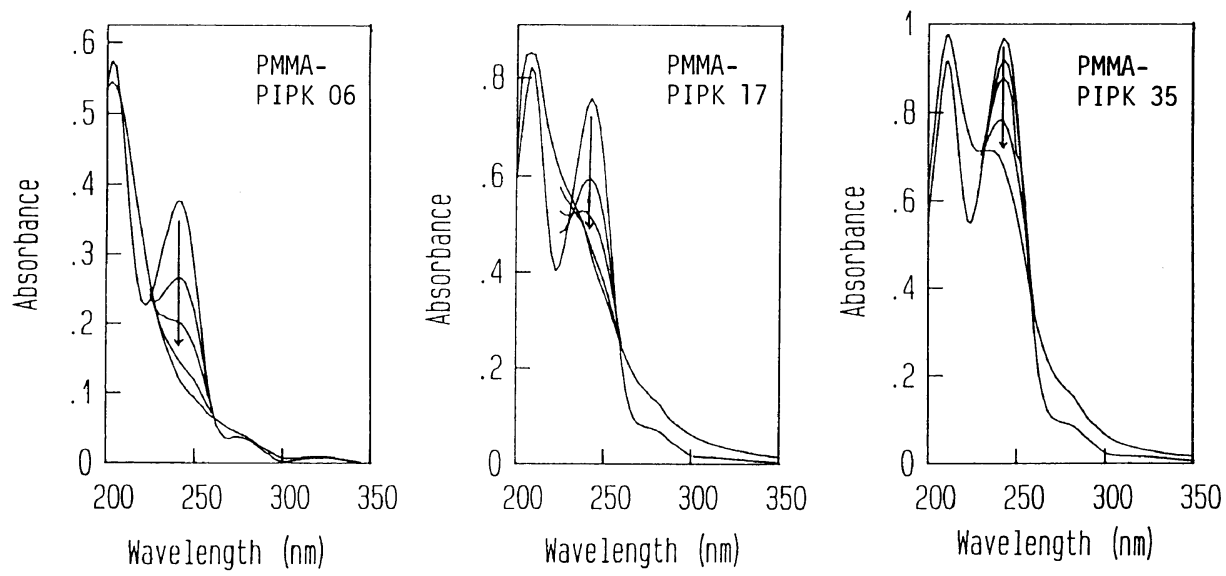

Figure 3. UV spectra of PMMA-PIPK before and after irradiation at $254 \mathrm{~nm}$ (solid film on a quartz plate). Incident dose: 0, 407, 851, 1630, 3250 $\mathrm{mJ} \mathrm{cm}^{-2}$. Left: PMMA-PIPK 06, $434 \mathrm{~nm}$ thick; middle: PMMA-PIPK 17, $339 \mathrm{~nm}$ thick; right: PMMA-PIPK 35, $335 \mathrm{~nm}$ thick. 
Positive-Working Resist Performance as a Function of PIPK Content

Characteristic curves were obtained with the PMMA copolymers containing various amounts of PIPK after exposure to $254 \mathrm{~nm}$, $313 \mathrm{~nm}$, and $365 \mathrm{~nm}$ monochromatic light, or mid and near UV radiation from a SHP $\mathrm{Hg}$ lamp with no filter. A series of characteristic curves after $254 \mathrm{~nm}$ exposure, development with methyl isobutyl ketone (MIBK) (7) + xylene (3) at $23^{\circ} \mathrm{C}$ for $120 \mathrm{~s}$, and rinse with isopropanol (IPA) (1) + xylene (1) for $60 \mathrm{~s}$, are shown in Figure 4 . Sensitivity, $D_{400}$, relative sensitivity to PMMA, RS, and contrast, $\gamma$, are summarized in Table III, and compared with those under different exposing, developing and rinse conditions. PMMA has no absorption,

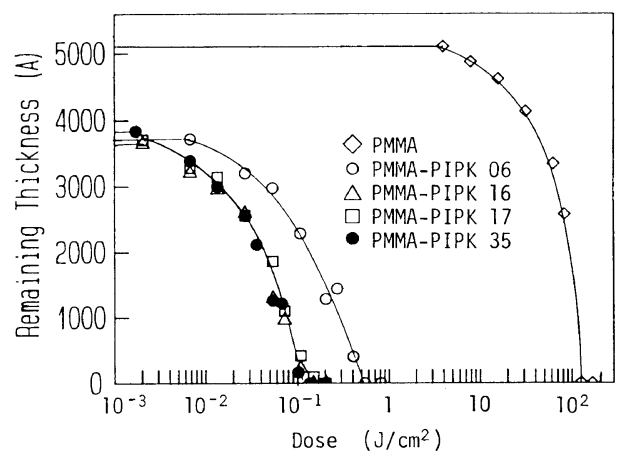

Figure 4. Effects of PIPK content on resist characteristics after $254 \mathrm{~nm}$ exposure. Development: MIBK (7) + xylene (3), $23^{\circ} \mathrm{C}, 120 \mathrm{~s}$; rinse: IPA (1) + xylene (1), $60 \mathrm{~s}$. and hence no sensitivity at $313 \mathrm{~nm}$ and $365 \mathrm{~nm}$. As is seen in Figure 4 and Table III, PMMA-PIPK 16 showed the highest sensitivity of $140 \mathrm{~mJ} \mathrm{~cm}^{-2}$, which was 810 times as large as that of PMMA. Sensitivity seemed saturated at this PIPK content, and did not increase further as the content became larger than $16 \mathrm{~mol} \%$. This may be ascribed to the insufficient bleaching characteristics mentioned in the previous section.

The characteristic curves after $365 \mathrm{~nm}$ exposure, development with MIBK at $25^{\circ} \mathrm{C}$ for $90 \mathrm{~s}$, and rinse with IPA for $15 \mathrm{~s}$, are shown in Figure 5. In this case, sensitivity increased as PIPK content became larger. A similar tendency was observed in the cases of $313 \mathrm{~nm}$ and the SHP Hg lamp exposure. The sensitivity

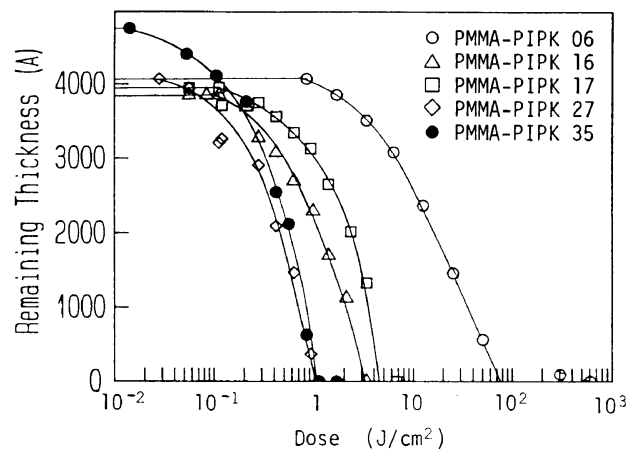

Figure 5. Effects of PIPK content on resist characteristics after $365 \mathrm{~nm}$ exposure. Development: MIBK, $25^{\circ} \mathrm{C}, 90 \mathrm{~s}$; rinse: IPA, $15 \mathrm{~s}$.

Table III. Sensitivity $D_{400}\left(\mathrm{~J} \mathrm{~cm}^{-2}\right)$, relative sensitivity to PMMA RS, and contrast $\gamma$

\begin{tabular}{|c|c|c|c|c|c|c|}
\hline Exposure & SHP & Hg lamp & $254 \mathrm{~nm}$ & $313 \mathrm{~nm}$ & \multicolumn{2}{|c|}{$365 \mathrm{~nm}$} \\
\hline $\mathrm{D}$ and $\mathrm{R}$ conditions & & A & A & A & A & B \\
\hline Polymer & \multicolumn{2}{|c|}{$D_{400}(\mathrm{RS}) / \gamma$} & $D_{400}(\mathrm{RS}) / \gamma$ & $D_{400} / \gamma$ & $D_{400} / \gamma$ & $D_{400} / \gamma$ \\
\hline PMMA & 32 & $(1.0) / 3.9$ & $(1.0) / 4.3$ & - & - & - \\
\hline PMMA-PIPK 06 & 1.5 & $(22) / 1.6$ & $0.32(350) / 1.3$ & $4.0 / 1.8$ & $13 / 0.89$ & $75 / 1.1$ \\
\hline PMMA-PIPK 16 & 0.41 & $(77) / 1.8$ & $0.14(810) / 1.4$ & $0.58 / 1.4$ & $1.7 / 1.4$ & $3.8 / 1.1$ \\
\hline PMMA-PIPK 17 & 0.60 & $(53) / 1.3$ & $0.15(740) / 1.3$ & $1.1 / 1.3$ & $2.8 / 1.7$ & $6.9 / 1.1$ \\
\hline PMMA-PIPK 27 & & & & & $0.61 / 1.5$ & $1.1 / 1.2$ \\
\hline PMMA-PIPK 35 & 0.29 & $(110) / 2.0$ & $0.14(800) / 1.4$ & $0.25 / 1.8$ & $0.39 / 2.4$ & $0.82 / 2.3$ \\
\hline
\end{tabular}

A: Development, MIBK(7) + xylene (3), $23^{\circ} \mathrm{C}, 120 \mathrm{~s}$; Rinse, IPA (1) + xylene (1), $60 \mathrm{~s}$.

B: Development, MIBK, $\quad 25^{\circ} \mathrm{C} ; 90 \mathrm{~s}$; Rinse, IPA, $15 \mathrm{~s}$. 
of PMMA-PIPK 35 was 110 times as large as that of PMMA after the SHP $\mathrm{Hg}$ lamp exposure, which coincides with the value reported by Nate et al. ${ }^{1}$ The highest sensitivities obtained with PMMA-PIPK 35 after $313 \mathrm{~nm}$ and $365 \mathrm{~nm}$ exposure were $250 \mathrm{~mJ} \mathrm{~cm}^{-2}$ and $390 \mathrm{~mJ} \mathrm{~cm}^{-2}$, respectively.

No definite correlation was found between contrast, $\gamma$, and PIPK content in this experiment. As is seen in Table III, sensitivity and contrast depended upon developing and

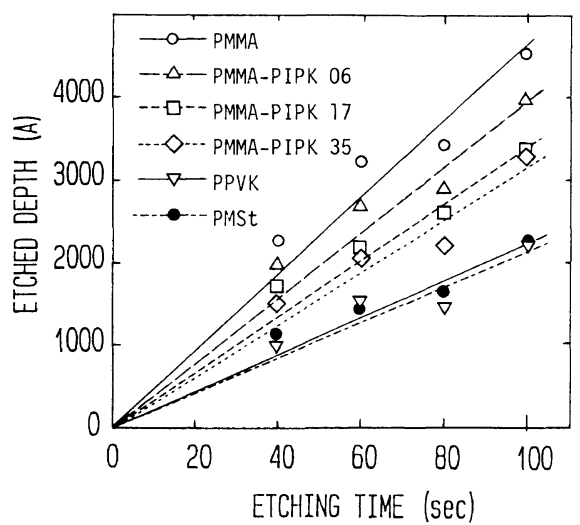

Figure 6. Etched depth $v s$, etching time for PMMAPIPK. $\mathrm{O}_{2}$ pressure, 0.2 Torr; $13.56 \mathrm{MHz}$ discharge power, $50 \mathrm{~W}$ (forward/reverse $=200 \mathrm{~W} / 150 \mathrm{~W}$ ).

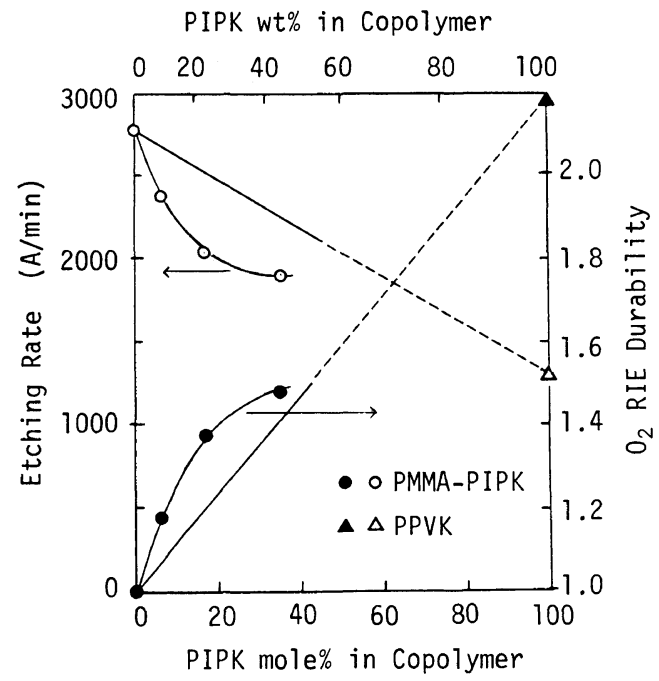

Figure 7. Effects of PIPK content on etching rate and $\mathrm{O}_{2}$ RIE durability for PMMA-PIPK. rinse conditions, and they may be improved further under more appropriate conditions.

The depth measured after $\mathrm{O}_{2} \mathrm{RIE}$ is plotted against the etching time in Figure 6 for a series of PMMA copolymers and the controls. The etching rate and the $\mathrm{O}_{2}$ RIE durability calculated from Figure 6 are plotted against PIPK content in Figure 7. As clearly shown by this figure, the etching rate decreased and durability increased as PIPK content became larger. PMMA-PIPK 35 was 1.5 times as durable as PMMA, and 0.7 times as durable as PPVK and PMSt, the durabilities of which were comparable to that of novolac resists. ${ }^{11}$

Generally speaking, the sensitivity and dry-etching durability of positive-working resists are in a trade-off relationship. However, it should be noted that copolymerization of PIPK enhanced sensitivity and durability at the same time. When the results in Figure 7 are examined in more detail, the etching rate of the copolymer is observed to be smaller than the averaged value calculated by following the weight-percent or mole-percent additivity based on the constituent monomer unit, as also found in the case of plasma etching of PMMA-MSt copolymers. ${ }^{12,13}$ The smaller rate suggests that some etchant migration or energy transfer mechanism is working to deactivate and prevent the copolymer from degrading after the attack by ions and neutral active species in the RIE atmosphere.

\section{Correlation among Molar Absorptivity, Quan- tum Yield and Resist Sensitivity}

Assuming that the wavelength dependence of the quantum yield for main chain scission measured with PSt-PIPK holds also for that of PMMA-PIPK (the ratio among the three $\Phi_{\text {cs }}$ values at the different wavelength is common for both copolymers), percent absorption by solid films of $400 \mathrm{~nm}$ thick, the number of breaks per unit irradiation energy, and the radiation energy required to get unit number of breaks $\left(E_{\mathrm{n}}\right)$ were calculated and are shown in Table IV. In this calculation, nano moles of 
Table IV. Percent absorption by solid films of $400 \mathrm{~nm}$ thick, break per unit irradiation energy $\left(\mathrm{B} \mathrm{J}^{-1}\right)$, and radiation energy required to get nano moles of break $\left(E_{\mathrm{n}}\right)$

\begin{tabular}{|c|c|c|c|c|c|c|c|c|c|c|}
\hline & & \multicolumn{3}{|c|}{$254 \mathrm{~nm}$} & \multicolumn{3}{|c|}{$313 \mathrm{~nm}$} & \multicolumn{3}{|c|}{$365 \mathrm{~nm}$} \\
\hline \multirow[t]{3}{*}{$\begin{array}{l}\text { PSt-PIPK } \\
\text { PMMA-PIPK }\end{array}$} & & \multicolumn{3}{|c|}{$\begin{array}{c}\Phi_{\mathrm{cs}}=0.19 \\
\varepsilon=7600\end{array}$} & \multicolumn{3}{|c|}{$\begin{array}{c}\Phi_{\mathrm{cs}}=0.36 \\
\varepsilon=86\end{array}$} & \multicolumn{3}{|c|}{$\begin{array}{c}\Phi_{\mathrm{cs}}=0.26 \\
\varepsilon=7.7\end{array}$} \\
\hline & $\begin{array}{c}\text { PIPK } \\
\text { conc. C }\end{array}$ & $\% \mathrm{Abs}^{\mathrm{a}}$ & $\mathrm{B} \mathrm{J}^{-1 \mathrm{~b}}$ & $E_{\mathrm{n}}^{\mathrm{c}}$ & $\% \mathrm{Abs}^{\mathrm{a}}$ & B J $\mathrm{J}^{-1} \mathrm{~b}$ & $E_{\mathrm{n}}^{\mathrm{c}}$ & $\% \mathrm{Abs}^{\mathrm{a}}$ & $\mathrm{B} \mathrm{J}^{-1 \mathrm{~b}}$ & $E_{\mathrm{n}}^{\mathrm{c}}$ \\
\hline & $\mathrm{moll}^{-1}$ & \multicolumn{3}{|c|}{$\times 10^{-7}$} & \multicolumn{3}{|c|}{$\times 10^{-8}$} & \multicolumn{3}{|c|}{$\times 10^{-10}$} \\
\hline PMMA-PIPK 06 & $0.56_{5}$ & 32.7 & $1.3_{2}$ & 0.0076 & $0.44_{7}$ & $0.42_{1}$ & 0.24 & 0.040 & $3.1_{8}$ & 3.1 \\
\hline PMMA-PIPK 16 & $1.4_{7}$ & 64.3 & $2.6_{0}$ & 0.0038 & $1.1_{6}$ & $1.0_{9}$ & 0.092 & $0.10_{4}$ & $8.2_{6}$ & 1.2 \\
\hline PMMA-PIPK 17 & $1.5_{8}$ & 66.8 & $2.7_{0}$ & 0.0037 & $1.2_{4}$ & $1.1_{7}$ & 0.085 & $0.11_{2}$ & $8.8_{9}$ & 1.1 \\
\hline PMMA-PIPK 35 & $3.0_{2}$ & 87.9 & $3.5_{5}$ & 0.0028 & $2.3_{5}$ & $2.2_{2}$ & 0.045 & $0.21_{4}$ & 17.0 & 0.59 \\
\hline
\end{tabular}

a $I / I_{0}=1-I_{\text {abs }} / I_{0}=10^{-\varepsilon c t} ; \% \mathrm{Abs}=I_{\mathrm{abs}} / I_{0} \times 100=\left(1-10^{-\varepsilon c t}\right) \times 100$ : where $c$, PIPK conc. in moll ${ }^{-1} ; t$, resist thickness; $400 \mathrm{~nm}=4 \times 10^{-5} \mathrm{~cm}$.

b Energy-Wavelength Relation (EWR): $\mathrm{J} \mathrm{mol}^{-1}=1195 \times 10^{5} / \lambda(\mathrm{nm}), 254 \mathrm{~nm} ; 4.70 \times 10^{5} \mathrm{~J} \mathrm{~mol}^{-1}, 313 \mathrm{~nm} ; 3.82 \times$ $10^{5} \mathrm{~J} \mathrm{~mol}^{-1}, 365 \mathrm{~nm} ; 3.27 \times 10^{5} \mathrm{~J} \mathrm{~mol}^{-1} .{ }^{10} \mathrm{~B} \mathrm{~J}^{-1}=(\% \mathrm{Abs} / 100) / \mathrm{EWR} \times \Phi_{\mathrm{cs}}, \mathrm{mol} \mathrm{J}^{-1}$, assuming that the ratio among the three $\Phi_{\mathrm{cs}}$ values is common for both PSt-PIPK and PMMA-PIPK.

c $E_{\mathrm{n}}=10^{-9} /\left(\mathrm{B} \mathrm{J}^{-1}\right), \mathrm{J}$ (nmol break $)^{-1}$, where $10^{-9}$ is a constant without physical meaning.

breaks were used as the unit break (this has no physical meaning, but just a constant), because the magnitude of $E_{\mathrm{n}}$ becomes of the same order as that of $D_{400}$ at $365 \mathrm{~nm}$ in Table III. However, $D_{400}$ s at $313 \mathrm{~nm}$ and $254 \mathrm{~nm}$ are 6-17 times and $36-50$ times as large as the $E_{\mathrm{n}} \mathrm{s}$ at the corresponding wavelength, respectively. Namely, the sensitivity observed is much lower than expected at shorter wavelength. The reason is not clear at present, but we can speculate the following four possibilities: i) photon energy may not be absorbed selectively by the chromophore in the polymer matrix in the case of irradiation at shorter wavelength, ii) the main chain may not degrade effectively in solid phase, iii) scission may not bring about effective increase of dissolution rate of the resist film into the developer, or iv) developing conditions may not have been fully optimized yet.

When $D_{400} \mathrm{~s}$ and $E_{\mathrm{n}} \mathrm{s}$ at $365 \mathrm{~nm}$ of the copolymers with different PIPK contents are compared, $\left(D_{400}\right.$ of PMMA-PIPK 35$) /\left(D_{400}\right.$ of PMMA-PIPK 06) is $1 / 33$, while the ratio of $E_{\mathrm{n}} \mathrm{s}$ is $1 / 5.3$. It is certain that sensitivity increases as the PIPK content becomes larger, but the sensitivity increase is larger than that expected from the number of main chain scission. Similar correlation is observed between $D_{400}$ and $E_{\mathrm{n}}$ at $313 \mathrm{~nm}$. These results suggest that the sensitivity of the positive-working resist, namely the dissolution rate difference between the exposed and the unexposed areas greatly depends upon the number or density of the main chain scission.

\section{CONCLUSION}

Quantum yield for main chain scission of PIPK copolymer with styrene after $254 \mathrm{~nm}$ exposure was measured to be 0.19 , which was lower than at $313 \mathrm{~nm}$ and $365 \mathrm{~nm}$. Copolymerization of PIPK with MMA enhanced sensitivity without decreasing, but rather with increasing, $\mathrm{O}_{2}$ RIE durability. The MMA copolymer containing $16 \mathrm{~mol} \%$ PIPK had 810 times large sensitivity of PMMA, though the bleaching characteristics were insufficient at $254 \mathrm{~nm}$ light irradiation at room temperature. The copolymer containing $35 \mathrm{~mol} \%$ of PIPK showed sensitivity of $250 \mathrm{~mJ} \mathrm{~cm}^{-2}$ at $313 \mathrm{~nm}$ and $390 \mathrm{~mJ} \mathrm{~cm}^{-2}$ at $365 \mathrm{~nm}$ light irradiation. 
These values are very high, compared with 140 $\mathrm{mJ} \mathrm{cm}{ }^{-2}$ at $254 \mathrm{~nm}$ with PMMA-16 $\mathrm{mol} \%$ PIPK copolymer, when very weak absorption in mid and near UV region is taken into account.

\section{REFERENCES}

1. K. Nate and T. Kobayashi, J. Electrochem. Soc., 128, 1394 (1981).

2. I. Naito, K. Koga, A. Kinoshita, and W. Schnabel, Eur. Polym. J., 16, 109 (1980).

3. I. Naito, K. Tashiro, and A. Kinoshita, $J$. Photochem., 23, 73 (1983).

4. K. Sugita, T. Kilp, and J. E. Guillet, J. Polym. Sci., Polym. Chem. Ed., 14, 1901 (1976).

5. H. C. Ng and J. E. Guillet, Macromolecules, 18, 2294 (1985).
6. J. Brandrup and E. H. Immergut, Ed., "Polymer Handbook," 3rd ed, John Wiley and Sons, New York, N.Y., 1989, pp VII-11 and pp VII-15.

7. S. L. Murov, "Handbook of Photochemistry," Mercel Dekker Inc., New York, N.Y., 1973, pp 119-123.

8. C. G. Hatchard and C. A. Parker, Proc. R. Soc. London, Ser., A, 235, 518 (1956).

9. T. L. Nemzek and J. E. Guillet, Macromolecules, 10, 94 (1977).

10. J. E. Guillet, "Polymer Photophysics and Photochemistry," Cambridge Univ. Press, London, 1985, pp 264-294 and pp 5.

11. H. Gokan, S. Esho, and Y. Ohnishi, J. Electrochem. Soc., 130, 143 (1983).

12. K. Sugita, N. Ueno, M. Funabashi, Y. Yoshida, Y. Doi, S. Nagata, and S. Sasaki, Polym. J., 10, 1091 (1985).

13. N. Ueno, Y. Doi, K. Sugita, S. Sasaki, and S. Nagata, J. Appl. Polym. Sci., 34, 1677 (1987). 